\title{
Pulmonary Tuberculosis Management: 2015 Update
}

\author{
Lia D’Ambrosio', Rosella Centis', Marco Mantero², Giovanni Battista Migliori' and Francesco Blasi²
}

${ }^{1}$ WHO Collaborating Centre for Tuberculosis and Lung Diseases, Fondazione S. Maugeri, IRCCS, Tradate, Italy; ${ }^{2}$ Dipartimento Fisiopatologia Medico-Chirurgica

e dei Trapianti, University of Milan, IRCCS Fondazione Cà Granda, Milan, Italy

\section{ABSTRACT}

Tuberculosis, currently killing more than 3,500 people every day, continues to be a first-class health priority in terms of incidence and mortality. The 2014 WHO Global Report estimates that nine million incident cases of tuberculosis and 1.5 million deaths occurred in 2013. The aim of the present review is to update the reader on the principles of modern anti-tuberculosis treatment, describe the regimens recommended by the WHO for drug-resistant and multidrug-resistant/extensively drug-resistant tuberculosis cases, and describe the trials presently underway on new regimens vis-à-vis the availability of new drugs like delamanid, bedaquiline, and pretomanid and several re-proposed drugs including linezolid and meropenem clavulanate. We performed a non-systematic review based on historical trial results as well as on recent literature and WHO guidelines, with special focus on the approach to manage multidrug-resistant and extensively drug-resistant tuberculosis. The new, innovative, global public health interventions, recently approved by the WHO and known as "End Tuberculosis Strategy", support the vision of a tuberculosis-free world with zero death, zero disease, and zero suffering due to tuberculosis. While rapid diagnosis and effective treatment of (infectious) cases are the pillars of tuberculosis control, a more aggressive approach based on diagnosis and treatment of latently infected individuals has been proposed in the context of tuberculosis elimination to ensure future generations free of the disease. Adequate, universally accessed treatment is a prerequisite to reach tuberculosis elimination. New shorter, cheap, safe, and effective anti-tuberculosis regimens are necessary to boost tuberculosis elimination. (BRN Rev. 2015;1:26-38)

Corresponding author: Francesco Blasi, francesco.blasi@unimi.it

Key words: MDR-TB. Prevention. Treatment. Tuberculosis (TB). XDR-TB. 


\section{INTRODUCTION}

Tuberculosis (TB), originating over 400 centuries ago in Africa, is caused by Mycobacterium tuberculosis. Killing currently $>3,500$ people every day, TB continues to be a first-class health priority in terms of incidence and mortality, together with HIV/AIDS and malaria. The 2014 World Health Organization (WHO) Global Report estimates that nine million incident cases of TB and 1.5 million deaths occurred in $2013^{1}$.

The rise in the number of $M$. tuberculosis isolates resistant to first-line (multidrug-resistant TB [MDR-TB], i.e. resistant to at least isoniazid and rifampicin) and second-line (extensively drug resistant [XDR], i.e. resistant to any fluoroquinolones and to at least one of the second-line injectable drugs, amikacin, capreomycin, and kanamycin on top of isoniazid and rifampicin) drugs is posing a real threat to global TB control and elimination efforts ${ }^{2-5}$. The WHO estimated that in 2013, the prevalence of MDR-TB among the new and re-treated cases was, respectively, 3.5 and $20.5 \%$, with $9 \%$ of them being XDR-TB ${ }^{1,6}$.

Unfortunately, at the global level, out of the estimated 300,000 MDR-TB cases, only 136,000 $(45.3 \%)$ are diagnosed and 97,000 (32.3\%) are treated using adequate regimens based on drug-susceptibility testing (DST). Consequently, the treatment success rate of MDR-TB is low $(48 \%)$, and that of the XDR-TB cases with advanced resistance patterns is very low $(<20 \%)^{1,7,8}$.

The aim of the present review is to update the reader on the principles of modern anti-TB treatment, describe the regimens recommended by the WHO for drug-resistant and MDR/XDR-TB cases, and describe the trials presently ongoing on new regimens vis-à-vis the availability of new drugs like delamanid, bedaquiline, and pretomanid.

A non-systematic review based on historical trials results as well as on recent literature and WHO guidelines has been performed.

\section{The rationale of modern short-course chemotherapy}

Mycobacterium tuberculosis is a slow-growing aerobic organism with the capacity to remain dormant for long periods of time. Prolonged treatment with multiple drugs is then necessary to ensure both relapse-free cure and prevention of drug-resistance. The results of any treatment effort are determined by a combination of bacteriological (e.g. number and metabolic conditions of the bacilli), environmental (anatomical and biochemical; e.g. oxygen tension and $\mathrm{pH}$ level) and pharmacological factors (e.g. drug dosage, combination and treatment duration) $)^{9-11}$.

Preventing the emergence of drug resistance, as early studies from 1960s have demonstrated ${ }^{11}$, is of paramount importance; at least two active drugs are necessary as mono-therapy leads to treatment failure and relapse.

There are three main actions of anti-TB drugs ${ }^{9-11}$ :

- Bactericidal action, e.g. the ability to rapidly kill actively growing bacilli, i.e. isoniazid $(\mathrm{H})$, and to a lesser extent rifampicin (R), pyrazinamide $(\mathrm{Z})$ and streptomycin $(\mathrm{S})$;

- Sterilizing action, e.g. the capacity to kill the semi-dormant organisms, e.g. $\mathrm{R}$ and $\mathrm{Z}$; and 
- Prevention of emergence of bacillary resistance, e.g. $\mathrm{H}$ and $\mathrm{R}$; and, with a lower efficacy, S, ethambutol (E) and Z.

Anti-TB treatment has an intensive and a continuation phase. The intensive phase of treatment kills both actively growing and semi-dormant bacilli, ensuring individual benefit for the patient, and reducing transmission in the community as well as the probability to select resistant mutants. During the intensive phase of treatment, at least two bactericidal drugs ( $\mathrm{H}$ and $\mathrm{S}$ or $\mathrm{H}$ and $\mathrm{R}$ ) are necessary. $\mathrm{Z}$ is added because of its brilliant activity in the acidic environment of the pulmonary cavities, and its capacity to kill semi-dormant bacilli not destroyed by other drugs. E, although bacteriostatic, is helpful in case of initial resistance to a single drug or when the initial bacillary load is high.

Appropriate multidrug combinations (including 3-5 drugs) are likely to contain at least two drugs able to kill the pre-existing mono-drug-resistant spontaneous mutants among wild strains. In case of mono-resistance to a first-line drug ( $\mathrm{R}$ excluded), the chances of a favorable outcome are reasonably high if four drugs are prescribed in the intensive phase of treatment ${ }^{12}$.

The continuation phase (usually including $\mathrm{H}$ and $\mathrm{R}$ for new cases) eliminates most residual bacilli, reducing the probability of failure and relapse. As the bacilli are no longer replicating actively, the probability of selecting drug-resistant mutants is low ${ }^{13}$.

\section{MANAGING DRUG-SUSCEPTIBLE TUBERCULOSIS}

The current 2004 WHO-recommended treatment regimens for new cases, approved TB drugs, and their dosage are summarized in table 1 . The $\mathrm{WHO}$ has started the procedures to revise these guidelines.

The recommendations ${ }^{14}$ clearly distinguish between new cases (e.g. patients diagnosed with $\mathrm{TB}$, who have never previously received anti-TB drugs for more than one month) and retreatment cases (e.g. those treated previously for more than 30 days). New TB cases (irrespective of HIV-status) should be treated with a six-month regimen of HRZE for the first two months ("intensive phase"), followed by HR for the remaining four months ("continuation phase $\left.\mathrm{e}^{\prime \prime}\right)^{14}$. Longer treatments are not recommended as clinical trials have not not confirmed clinical superiority.

Although daily dosage is recommended for the entire duration of treatment (and particularly during the intensive phase), the threetimes weekly approach is allowed if directly observed therapy is ensured.

Fixed-dose combination formulations are recommended to treat $\mathrm{TB}$, based on evidence of no significant differences between fixed-dose combinations and separate TB drug formulations in acquiring drug resistance, achieving bacteriological conversion, or producing adverse events ${ }^{15}$. Furthermore, fixed-dose combinations simplify TB therapy at the programmatic level, although no evidence exists that these formulations improve treatment outcomes or patient adherence.

The WHO has recently published its new "End TB Strategy"1,16 based on three pillars: the first pillar includes prevention, diagnostic and treatment interventions, the second the socio-economic interventions beyond the TB 
TABLE 1. WHO-recommended treatment regimens for new and previously treated patients

\begin{tabular}{|c|c|c|c|c|c|c|c|c|}
\hline \multicolumn{4}{|c|}{ NEW TUBERCULOSIS CASES } & \multicolumn{5}{|c|}{$\begin{array}{l}\text { PREVIOUSLY TREATED TUBERCULOSIS CASES } \\
\text { Pending DST results (up to } 2-3 \text { months after the start of treatment) } \\
\text { PROBABILITY OF MDR-TB }\end{array}$} \\
\hline \multicolumn{2}{|c|}{ INTENSIVE PHASE } & \multicolumn{2}{|c|}{ CONTINUATION PHASE } & \multicolumn{4}{|c|}{$\begin{array}{l}\text { Medium or low } \\
\text { (relapse, lost to follow-up) }\end{array}$} & \multirow[t]{3}{*}{$\begin{array}{l}\text { High } \\
\text { (failure) }\end{array}$} \\
\hline \multirow[t]{2}{*}{ Duration } & \multirow[t]{2}{*}{ Anti-TB drugs } & \multirow[t]{2}{*}{ Duration } & \multirow[t]{2}{*}{ Anti-TB drugs } & \multicolumn{2}{|c|}{ INTENSIVE PHASE } & \multicolumn{2}{|c|}{ CONTINUATION PHASE } & \\
\hline & & & & Duration & Anti-TB drugs & Duration & Anti-TB drugs & \\
\hline \multirow[t]{2}{*}{2 months } & \multirow[t]{2}{*}{$\begin{array}{l}\text { Isoniazid (H) } \\
\text { Rifampicin (R) } \\
\text { Pyrazinamide (Z) } \\
\text { Ethambutol* (E) }\end{array}$} & \multirow[t]{2}{*}{4 months $^{\dagger}$} & \multirow[t]{2}{*}{$\begin{array}{l}\text { Isoniazid }(\mathrm{H})^{\#} \\
\text { Rifampicin }(\mathrm{R})^{\#} \\
\text { or } \\
\text { Isoniazid }(\mathrm{H})^{\#} \\
\text { Rifampicin }(\mathrm{R})^{\#} \\
\text { Ethambutol }(\mathrm{E})^{\#}\end{array}$} & 2 months & $\begin{array}{l}\text { Isoniazid (H) } \\
\text { Rifampicin (R) } \\
\text { Pyrazinamide (Z) } \\
\text { Ethambutol (E) } \\
\text { Streptomycin (S) }\end{array}$ & \multirow[t]{2}{*}{5 months } & \multirow{2}{*}{$\begin{array}{l}\text { Isoniazid (H) } \\
\text { Rifampicin (R) } \\
\text { Ethambutol (E) } \\
\text { To be changed } \\
\text { once DST } \\
\text { testing } \\
\text { results are } \\
\text { available }\end{array}$} & \multirow{2}{*}{$\begin{array}{l}\text { Empirical } \\
\text { MDR-TB } \\
\text { regimen } \\
\text { To be changed } \\
\text { once DST } \\
\text { testing results } \\
\text { are available }\end{array}$} \\
\hline & & & & 1 month & $\begin{array}{l}\text { Isoniazid (H) } \\
\text { Rifampicin (R) } \\
\text { Pyrazinamide (Z) } \\
\text { Ethambutol (E) }\end{array}$ & & & \\
\hline
\end{tabular}

*Ethambutol has to be prescribed in individuals with non-cavitary, sputum smear-negative pulmonary TB or with extra-pulmonary TB who are known to be HIV-negative. In TB meningitis, it should be replaced by streptomycin.

${ }^{t}$ When the level of isoniazid resistance among new cases is elevated and in-vitro isoniazid DST is not available, HRE regimen may be an acceptable alternative to HR regimen "WHO considers the 3 times per week continuation phase as acceptable alternative for any new TB patient receiving directly observed therapy WHO: World Health Organization; TB: tuberculosis; MDR-TB: multidrug-resistant tuberculosis; DST: drug susceptibility testing.

Adapted from: World Health Organization. The treatment of tuberculosis: guidelines-4th ed. ${ }^{14}$.

programmatic level (e.g. universal access, social protection, etc.) and the third, the research priorities.

As part of pillar 1, universal drug susceptibility testing (rapid DST with, for example GeneXpert ${ }^{17}$ and/or conventional with solid or liquid culture) is strongly recommended before prescribing the anti-TB regimen; however, this is not universally available yet in several developing countries. Re-treatment patients need special attention because of the risk of inducing drug resistance. Rapid tests for DST should be used whenever available to ensure an appropriate treatment regimen from the beginning as well as adequate infection control management in a specialized MDR-TB Centre $^{18,19}$. While awaiting DST results, these patients could be initially treated with an empiric regimen (i.e. HRZES for two months, followed by HRZE for one month and HRE for five months) only in settings where the prevalence of MDR-TB is medium or low.

\section{MANAGING MULTIDRUG RESISTANT AND EXTENSIVELY DRUG RESISTANT TUBERCULOSIS}

The emergence and spread of MDR-and XDRTB has attracted interest at different levels $^{1,20-23}$. Recently, M. tuberculosis strains that are resistant to all known drugs have been described in Italy $^{24}$ as well as in India and Iran ${ }^{25-27}$, leading to the new definition of "total drug resistance". However, this definition has not been approved by the WHO due to the difficulty to standardize the panel of drugs to be tested vis-à-vis the new drugs gradually entering in the anti-TB treatment arena. 
From the public health point of view, MDR/ XDR-TB is considered a serious threat for TB control and elimination ${ }^{1,21}$.

The prevalence of MDR-TB is particularly high in several countries belonging to the former Soviet Union, where 9-35\% of new cases and $\geq 50 \%$ of previously treated cases harbor MDR-TB strains ${ }^{1}$.

XDR-TB had been reported by 100 countries worldwide. Overall, 75 countries plus five territories globally reported representative data on the proportion of MDR-TB cases affected by XDR-TB, being 9\% (95\% CI: 6.5-11.5) in 2013. Fifteen of these 75 countries reported 10 or more XDR-TB cases. Among those countries, the proportion of MDR-TB cases affected by XDR-TB was highest in Georgia (20\%), Kazakhstan (22.7\%), Latvia (21.7\%), Lithuania $(24.8 \%)$, and Tajikistan (Dushanbe city and Rudaki district: $21 \%)^{1}$.

To combat the MDR/XDR-TB threat, the 53 Member States of WHO European Region have endorsed the five-year Consolidated Action Plan to Prevent and Combat M/XDR-TB 2011-2015

We have mentioned above how unsatisfactory the clinical outcome of MDR-TB cases is $1,6,29,30$. In the largest ever-published cohort of 9,153 MDR-TB cases from 32 observational cohorts supporting an individual data meta-analysis, the clinical outcomes were unacceptably poor (treatment success 54\%; default 23\%; failure/ relapse $8 \%$; death $15 \%)^{31}$. In XDR-TB cases and cases with resistance patterns beyond XDR, the outcomes were even worse, with treatment success ranging from 19 to $40 \%$, failure/relapse from 15 to $54 \%$, and death from 15 to $35 \% \%^{7,8}$.
TABLE 2. WHO groups of first-and second-line anti-tuberculosis drugs

\begin{tabular}{|c|c|}
\hline Group name & Anti-tuberculosis drugs \\
\hline $\begin{array}{l}\text { 1. First-line oral anti-TB } \\
\text { drugs }\end{array}$ & $\begin{array}{l}\text { Isoniazid (H) } \\
\text { Rifampicin (R) } \\
\text { Ethambutol (E) } \\
\text { Pyrazinamide (Z) } \\
\text { Rifabutin (Rfb) } \\
\text { Rifapentine (Rpt) }\end{array}$ \\
\hline $\begin{array}{l}\text { 2. Injectable anti-TB drugs } \\
\text { (injectable or parenteral } \\
\text { agents) }\end{array}$ & $\begin{array}{l}\text { Streptomycin (S) } \\
\text { Kanamycin }(\mathrm{Km}) \\
\text { Amikacin }(\mathrm{Am}) \\
\text { Capreomycin }(\mathrm{Cm})\end{array}$ \\
\hline 3. Fluoroquinolones (F0) & $\begin{array}{l}\text { Levofloxacin (Lfx) } \\
\text { Moxifloxacin (Mfx) } \\
\text { Gatifloxacin (Gfx) } \\
\text { Ofloxacin (Ofx) }\end{array}$ \\
\hline $\begin{array}{l}\text { 4. Oral bacteriostatic } \\
\text { second-line anti-TB } \\
\text { drugs }\end{array}$ & $\begin{array}{l}\text { Ethionamide (Eto) } \\
\text { Prothionamide (Pto) } \\
\text { Cycloserine (Cs) } \\
\text { Terizidone (Trd) } \\
\text { p-aminosalicylic acid (PAS) } \\
\text { p-aminosalicylate sodium (PAS-Na) }\end{array}$ \\
\hline $\begin{array}{l}\text { 5. Anti-TB drugs with } \\
\text { limited data on efficacy } \\
\text { and/or long-term safety } \\
\text { in the treatment of } \\
\text { drug-resistant TB. }\end{array}$ & $\begin{array}{l}\text { Bedaquiline (Bdq) } \\
\text { Delamanid (Dlm) } \\
\text { Linezolid (Lzd) } \\
\text { Clofazimine (Cfz) } \\
\text { Amoxicillin/Clavulanate (Amx/Clv) } \\
\text { Imipenem/Cilastatin (Ipm/Cln) } \\
\text { Meropenem (Mpm) } \\
\text { High-dose isoniazid (High dose H) } \\
\text { Thioacetazone (T) } \\
\text { Clarithromycin (Clr) }\end{array}$ \\
\hline
\end{tabular}

The challenges clinicians face when dealing with MDR-and XDR-TB cases include frequent occurrence of adverse events, limited availability of second-line anti-TB drugs, the relevant risk of acquiring further $M$. tuberculosis resistance, on top of associated conditions such as alcohol and drug abuse and problems in patient adherence.

The 2011 WHO MDR-TB guidelines ${ }^{32}$ have divided anti-TB drugs into groups, based on their efficiency and safety (Table 2). 
TABLE 3. WHO-recommended treatment regimen for multidrug-resistant tuberculosis

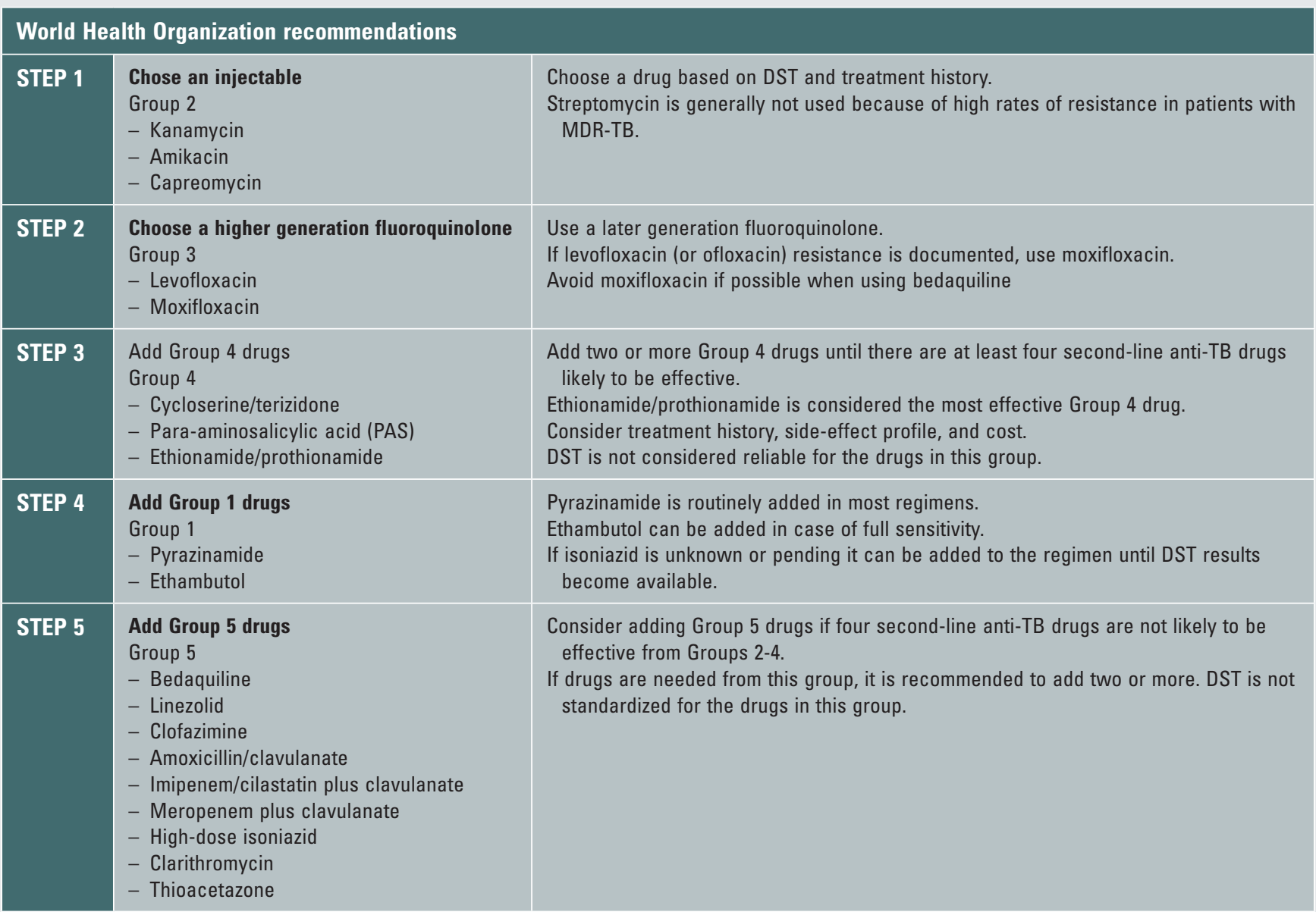

TB: tuberculosis; MDR-TB: multidrug-resistant tuberculosis; DST: drug susceptibility testing.

Adapted from: WHO Companion handbook to the WHO guidelines for the programmatic management of drug-resistant tuberculosis ${ }^{33}$.

The strategies for the treatment of drug-resistant TB (DR-TB) have recently been updated ${ }^{32,33}$. The treatment of mono-and poly-drug-resistant TB is largely based on the recommendations from the 2011 WHO Guidelines for the programmatic management of DR-TB mentioned above, which underwent systematic review and analysis of the best treatment evidence base ${ }^{28}$. Table 3 summarizes the stepwise approach recommended for the design of treatment regimens. There are presently two approaches TB programs are using, including both standardized and individualized regimens.
Suspected MDR-TB cases should be confirmed by DST whenever possible. In the absence of patient-specific DST, data from representative patient populations are used to develop and design standardized empiric treatment regimens, which are likely to include a sufficient number of active drugs to ensure treatment success.

However, the individualized approach has to be preferred. Each treatment regimen is designed based on both the patient's past history of TB treatment and the individual DST results. The recommended empiric regimen 
for MDR-TB treatment should include a minimum of four potentially active drugs: a later generation fluoroquinolone (moxifloxacin, gatifloxacin, or levofloxacin) and an injectable aminoglycoside (amikacin, capreomycin, or kanamycin), plus any first-line drug to which the isolate is susceptible such as pyrazinamide, plus the addition of one drug from group 4 (cycloserine, para-aminosalicylic acid, terizidone, prothionamide, or ethionamide) (Table 3). The drugs categorized as WHO class 5 should be included only if four potential active drugs are not available. The core principle is that at least four drugs to which $M$. tuberculosis is likely to be susceptible are needed.

The minimum duration of the intensive phase (using injectables) is eight months, while the continuation phase will last for 12-18 months. The total treatment duration recommended by the WHO based on the available evidence is at least 20 months. The duration of treatment should be guided by culture conversion: 18 months need to be added to the date of the first negative culture. Where patients show no clinical response and their $M$. tuberculosis cultures are consistently positive, the underlying causes should be identified. The most common causes are incorrect drug dosage, quality of drug supply, non-adherence factors, malabsorption, and comorbidities.

\section{NEW TRIALS AND NEW DRUGS}

Fluoroquinolones are being studied for their interesting bactericidal activity and potential capacity to reduce the treatment duration. Trials using new generation fluoroquinolone-containing (moxifloxacin and gatifloxacin) regimens indicate that they are unfortunately not effective in shortening TB treatment beyond the current recommended duration of six months. The REMoxTB trial (Rapid Evaluation of Moxifloxacin in Tuberculosis) was randomized, double-blind, and placebo-controlled. It evaluated two regimens in which either $\mathrm{E}$ or $\mathrm{H}$ was substituted by moxifloxacin in a single fourmonth combination therapy ${ }^{34}$. The OFLOTUB trial $^{35,36}$ evaluated a standard six-month regimen including $\mathrm{E}$ during the two-month intensive phase against a four-month regimen in which $\mathrm{E}$ was replaced with gatifloxacin during the intensive phase and continued, together with $\mathrm{R}$ and $\mathrm{H}$, during the continuation phase of treatment. The RIFAQUIN tri$\mathrm{al}^{37}$ evaluated two regimens in which moxifloxacin replaced $\mathrm{H}$ during the intensive phase of treatment. Although the results of these trials have not been as brilliant as expected, several phase III clinical trials are presently testing existing, repurposed, and new drugs. Several of these trials involve the new drugs, bedaquiline, delamanid, and pretomanid, previously known as PA-824.

Bedaquiline selectively targets the proton pump of adenosine triphosphate (ATP) synthesis, leading to inadequate ATP production and lack of intracellular energy supporting replication $^{38}$. The bactericidal activity of bedaquiline is superior to that of $H$ and $R^{38}$. The results of phase II trials suggest that a standard two-month treatment regimen with bedaquiline added to an optimized background regimen (OBR) designed as per WHO recommendations increase culture and sputum smear conversion rates while lowering acquired resistance to companion drugs in newly diagnosed MDR-TB cases ${ }^{39,40}$. Both the $\mathrm{WHO}^{41}$ and the US Centers for Disease Control and Prevention 
$(\mathrm{CDC})^{42}$ have published consistent recommendations supporting the use of bedaquiline under the following conditions: the dose of $400 \mathrm{mg}$ daily for two weeks (then $200 \mathrm{mg}$ three-times a week for 22 weeks) should be used; bedaquiline should be added to an OBR regimen to treat adult MDR-TB cases; pharmacovigilance needs to be in place; informed consent is compulsory and QT monitoring facilities have to be available ${ }^{41,42}$. The simultaneous use of bedaquiline and delamanid is not recommended because of the increased risk of QT prolongation and death ${ }^{41,42}$. Phase III trials of the use of bedaquiline to shorten the treatment duration are presently ongoing.

Both delamanid (previously known as OPC67683) and pretomanid inhibit the synthesis of mycolic acids of the mycobacterial wall, being active against replicating and anaerobic, non-replicating $M$. tuberculosis persisters. They have shown potentialities to improve treatment outcomes for MDR-TB ${ }^{5,43-51}$. They are currently in phase II/III clinical trials (Table 4$)^{45,46,48,50,51}$. Based on the available evidence, the $\mathrm{WHO}^{47}$ recommends the use of delamanid at a dose of $100 \mathrm{mg}$ twice daily for six months, added to OBR in adults, when pharmacovigilance is in place and informed consent ensured. Although anecdotal evidence suggests that delamanid is effective and safe in children ${ }^{5}$, two clinical trials (NCT01859923 and NCT01856634) are presently investigating delamanid in the treatment of pediatric MDR-TB.

Diacon, et al. assessed the 14-day early bactericidal activity of a regimen composed of pretomanid, moxifloxacin, and $Z$, which proved to be significantly higher than that of bedaquiline alone, bedaquiline plus $Z$, bedaquiline plus pretomanid (but not to pretomanid plus $\mathrm{Z}$ ) and comparable to that of the standard treatment regimen (HRZ with $S$ or $E$ ). Interesting$1 \mathrm{y}$, the addition of $\mathrm{Z}$ increased the activity of both bedaquiline and pretomanid $39,48-50$.

In a recent phase $\mathrm{IIb}$ trial, the bactericidal activity of a new eight-week regimen including moxifloxacin, pretomanid, $\mathrm{Z}$, and clofazimine was compared to that of the standard (WHO-recommended) anti-TB regimen for drug susceptible and DR-TB. The new regimen yielded higher bactericidal activity than the current WHO-recommended regimen after two months of treatment ${ }^{51}$.

\section{RE-PROPOSED DRUGS}

Among re-proposed anti-TB drugs, linezolid and meropenem clavulanate recently raised special interest.

Linezolid, a first-generation oxazolidinone, proved to be effective against $M$. tuberculosis when added to OBR, although adverse events were common ${ }^{52-56}$. A recent meta-analysis ${ }^{56}$ based on individual data provided updated evidence on efficacy, safety, and tolerability of linezolid, as well as indirect evidence that a proper treatment drug monitoring approach to drug dosage can reduce linezolid toxicity ${ }^{57}$.

An interesting study from The Netherlands ${ }^{58}$ shows that clarithromycin is able to boost the blood levels of linezolid, so that a lower dose of drug can be administered; less adverse events are then expected together with economic savings. The available evidence suggest 
TABLE 4. Summary of the main new anti-tuberculosis drugs with the most relevant studies and related findings

\begin{tabular}{|c|c|c|c|c|c|}
\hline Drug & Drug class & $\begin{array}{l}\text { Study ID Number/ } \\
\text { Clinical trial } \\
\text { registration number }\end{array}$ & $\begin{array}{l}\text { Clinical } \\
\text { trial } \\
\text { phase }\end{array}$ & Trial findings & Reference \\
\hline $\begin{array}{l}\text { Bedaquiline } \\
\text { (TMC207) }\end{array}$ & Diarylquinoline & $\begin{array}{l}\text { TMC207-TIDP13-C208/ } \\
\text { NCT00449644 }\end{array}$ & Phase II & $\begin{array}{l}\text { The addition of Del (TMC207) to OBR reduced the time } \\
\text { to } \mathrm{C} \text { conversion, vs. OBR (HR: } 11.8 ; 95 \% \mathrm{CI}: 2.3-61.3 ; \mathrm{p} \\
=0.003 \text { ) while increasing the proportion of } \mathrm{C} \\
\text { converters ( } 48 \text { vs. } 9 \% \text { ). The mean } \mathrm{CFU} \log _{10} \text { count in } \\
\text { SS declined more rapidly in the Del group than in OBR } \\
\text { one. No significant differences in average plasma Del } \\
\text { concentrations were noted between patients with and } \\
\text { without } \mathrm{C} \text { conversion. Most observed AE were mild to } \\
\text { moderate. }\end{array}$ & Diacon, et al. ${ }^{39}$ \\
\hline $\begin{array}{l}\text { Delamanid } \\
\text { Trial 204 } \\
\text { (OPC 67683) }\end{array}$ & Nitroimidazole & $\begin{array}{l}\text { 242-07-204/ } \\
\text { NCT00685360 }\end{array}$ & Phase II & $\begin{array}{l}\text { Among patients receiving OBR plus } 100 \mathrm{mg} \text { of Del BID, } \\
45.4 \% \text { achieved } C \text { conversion at } 2 \text { months, vs. } 29.6 \% \text { of } \\
\text { patients receiving OBR ( } p=0.008 \text { ). As compared with } \\
\text { OBR, the group receiving OBR+ Del } 200 \mathrm{mg} \text { BID } \\
\text { yielded higher proportion of SS and C conversion } \\
(41.9 \% ; p=0.04) \text {. Most AE were mild to moderate and } \\
\text { evenly distributed across groups. Although no clinical } \\
\text { events due to OT prolongation on ECG were observed, } \\
\text { OT prolongation was reported significantly more } \\
\text { frequently in the delamanid groups. }\end{array}$ & Gler, et al. ${ }^{45}$ \\
\hline $\begin{array}{l}\text { Delamanid } \\
\text { Trial 208 } \\
\text { (OPC 67683) }\end{array}$ & Nitroimidazole & $\begin{array}{l}\text { 242-09-213/ } \\
\text { NCT01424670 }\end{array}$ & Phase III & $\begin{array}{l}\text { Patients participating in the previously reported Del } \\
\text { controlled trial and the subsequent open-label } \\
\text { extension trial were eligible to participate in a } \\
24 \text {-month observational study designed to capture } \\
\text { treatment outcomes. Favorable outcomes were } \\
\text { observed in } 143 / 192(74.5 \%) \text { patients receiving Del for } \\
\geq 6 \text { months, vs. } 126 / 229(55 \%) \text { patients receiving Del for } \\
\leq 2 \text { months. Mortality was reduced to } 1.0 \% \text { among } \\
\text { those receiving long-term Del vs. short-term/no Del } \\
\text { (8.3\%; } p=0.001) \text {. Treatment benefit was also observed } \\
\text { among XDR-TB patients. }\end{array}$ & $\begin{array}{l}\text { Skripconoka, } \\
\text { et al. }{ }^{46}\end{array}$ \\
\hline $\begin{array}{l}\text { Pretomanid } \\
\text { Trial NC-001 } \\
\text { (PA-824) }\end{array}$ & Nitroimidazole & $\begin{array}{l}\text { NC-001-(J-M-Pa-Z)/ } \\
\text { NCT01215851 }\end{array}$ & Phase II & $\begin{array}{l}\text { The mean } 14 \text {-day EBA of Pto (PA-824) + moxifloxacin }+Z \\
(\mathrm{n}=13 ; 0.233 ; \text { SD } 0.128) \text { was significantly higher than } \\
\text { that of Bdq }(14 ; 0.061 ; 0.068), B d q+Z(15 ; 0.131 ; 0.102) \text {, } \\
\text { Bdq + Pto }(14 ; 0.114 ; 0.050) \text {, but not Pto }+Z(14 ; 0.154 ; \\
0.040) \text {, and comparable with that of standard HRZE } \\
\text { treatment }(10 ; 0.140 ; 0.094) \text {. Treatments were well } \\
\text { tolerated and appeared safe. One patient on Pto + } \\
\text { moxifloxacin + Z was withdrawn because of corrected } \\
\text { OT interval changes exceeding pre-specified criteria. }\end{array}$ & Diacon, et al. ${ }^{48}$ \\
\hline
\end{tabular}

that a linezolid dose between 300 and $600 \mathrm{mg}$ per day is adequate to treat MDR-/XDR-TB when added to OBR ${ }^{52-61}$.

\section{Meropenem clavulanate is also active against} M. tuberculosis and appears to be well tolerated. In a case-control study ${ }^{62}$ it demonstrated, when added to linezolid-containing OBR, to improve sputum smear and culture conversion in MDRand XDR-TB cases. Further studies are necessary to define the role of this drug within the anti-MDR-TB armamentarium.

Other drugs, including sulfamides and mefloquine, have been used in difficult-to-treat cases, although the evidence is anecdotal ${ }^{63-65}$. 
TABLE 4. Summary of the main new anti-tuberculosis drugs with the most relevant studies and related findings (continued)

\begin{tabular}{|c|c|c|c|c|c|}
\hline Drug & Drug class & $\begin{array}{l}\text { Study ID Number/ } \\
\text { Clinical trial } \\
\text { registration number }\end{array}$ & $\begin{array}{l}\text { Clinical } \\
\text { trial } \\
\text { phase }\end{array}$ & Trial findings & Reference \\
\hline $\begin{array}{l}\text { Pretomanid } \\
\text { Trial NC-002 } \\
\text { (PA-824) }\end{array}$ & Nitroimidazole & $\begin{array}{l}\text { NC-002-(M-Pa-Z)/ } \\
\text { NCT01498419 }\end{array}$ & Phase II & 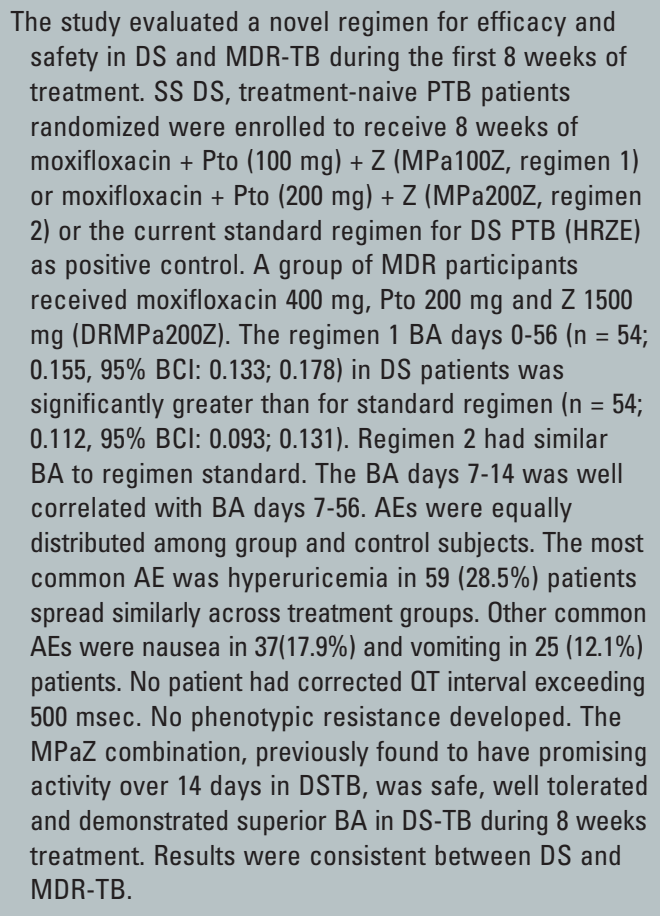 & Dawson, et al. ${ }^{51}$ \\
\hline $\begin{array}{l}\text { Pretomanid } \\
\text { Trial NC-003 } \\
\text { (PA-824) }\end{array}$ & Nitroimidazole & $\begin{array}{l}\text { NC-003-(C-J-Pa-Z)/ } \\
\text { NCT01691534 }\end{array}$ & Phase II & 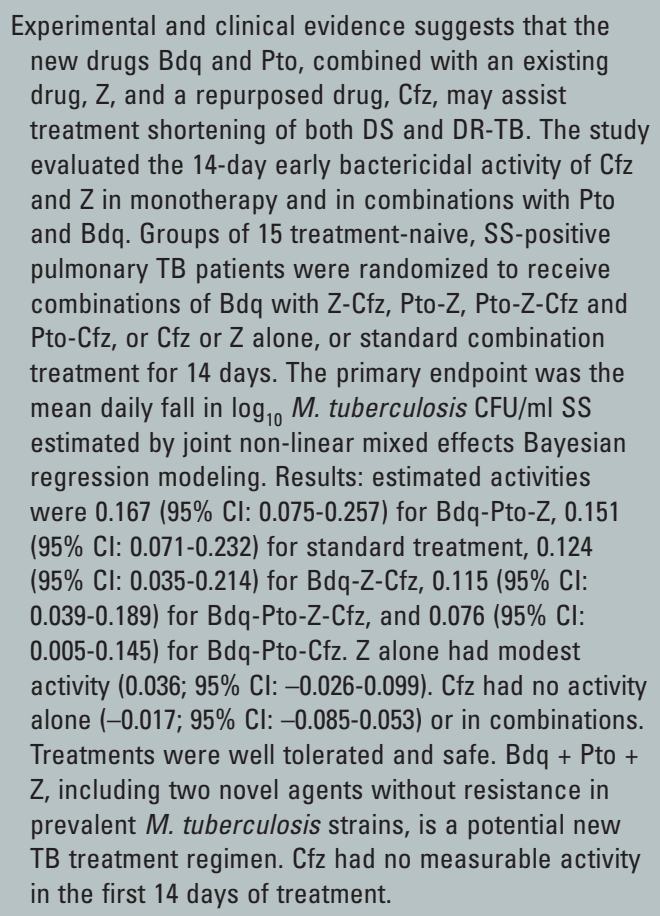 & Diacon, et al. ${ }^{50}$ \\
\hline
\end{tabular}

OBR: optimized background regimen; C: culture; HR: hazard ratio; Cl: confidence interval; CFU: colony-forming unit; SS: sputum smear; AE: adverse events; BCI: Bayesian credibility interval; BID: twice daily; $\mathrm{QT}$ : measure of the time between the start of the $\mathrm{Q}$ wave and the end of the T wave in the heart's electrical cycle; ECG: electrocardiogram; EBA: early bactericidal activity; DS: drug-susceptible; DR: drug-resistant; MDR-TB: multidrug-resistant tuberculosis; PTB: pulmonary tuberculosis; DR-TB: drug-resistant-tuberculosis; TB: tuberculosis; WBA: whole blood bactericidal activity; OB: once daily; MIC: minimum inhibitory concentration; H: isoniazid; R: rifampicin; Z: pyrazinamide; E: ethambutol; Bql: bedaquiline; Pto: pretomanid; Del: delamanid; Cfz: cloafazimine. 


\section{NEW EFFECTIVE ANTI-TUBERCULOSIS REGIMENS: A STEP FORWARD}

The new, innovative global public health intervention recently approved by the WHO and known as "End TB Strategy"1, supports the vision of a TB-free world with zero death, zero disease, and zero suffering due to $\mathrm{TB}^{66-68}$.

While rapid diagnosis and effective treatment of (infectious) cases are the pillars of TB control, a more aggressive approach based on diagnosis and treatment of latently infected individuals has been proposed in the context of TB elimination to ensure future, TB-free, generations.

Within the Pillar 1 adequate, universally accessed treatment is a prerequisite to reach TB elimination.

New shorter, cheap, safe, and effective anti-TB regimens are necessary to boost $\mathrm{TB}$ elimination ${ }^{69,70}$.

The new drugs have shown promising steps toward a new universal regimen ${ }^{51}$ that, bypassing the $\mathrm{H}$ and $\mathrm{R}$ bottleneck, allows to treat all HIV-coinfected patients (with no interference with antiretrovirals) independently from their drug-susceptible or DR status ${ }^{71}$.

There are obvious potentialities to shorten the treatment duration and, consequently, to improve patient adherence and reduce the selection of resistant mutants of $M$. tuberculosis.

The rational use of the existing drugs and regimens is necessary if we want to ensure them a long life ${ }^{72}$.

\section{FINANCIAL SUPPORT}

No funding was received by the authors.

\section{CONFLICT OF INTEREST}

All authors have no conflict of interest to declare.

\section{REFERENCES}

1. World Health Organisation. Global Tuberculosis report 2014. WHO/HTM/ TB/2014. Geneva, World Health Organization 2014. Available at: http:/ / www.who.int/tb/publications/global_report/en/

2. Diel R, Loddenkemper R, Zellweger JP, et al. Old ideas to innovate tuberculosis control: preventive treatment to achieve elimination. Eur Respir J. 2013;42:785-801.

3. D'Ambrosio L, Dara M, Tadolini M, et al. TB Elimination: theory and practice in Europe. Eur Respir J. 2014;43:1410-20.

4. Lönnroth K, Migliori GB, Abubakar I, et al. Towards tuberculosis elimination an action framework for low-incidence countries. Eur Respir J. 2015;45:928-52.

5. Esposito S, D'Ambrosio L, Tadolini M, et al. ERS/WHO Tuberculosis Consilium assistance with extensively drug-resistant tuberculosis management in a child: case study of compassionate delamanid use. Eur Respir J. 2014;44:811-5.

6. Skrahina A, Hurevich H, Zalutskaya A, et al. Alarming levels of drug-resistant tuberculosis in Belarus: results of a survey in Minsk. Eur Respir J. 2012;39:1425-31.

7. Falzon D, Gandhi N, Migliori GB, et al. Resistance to fluoroquinolones and second-line injectable drugs: impact on multidrug-resistant TB outcomes. Eur Respir J. 2013;42:156-68.

8. Migliori GB, Sotgiu G, Gandhi NR, et al. Drug resistance beyond extensively drug-resistant tuberculosis: individual patient data meta-analysis. Eur Respir J. 2013;42:169-79.

9. Mitchison DA. The diagnosis and therapy of tuberculosis during the past 100 years. Am J Respir Crit Care Med. 2005;171:699-706.

10. Mitchison DA. Bacteriological mechanisms in recent controlled chemotherapy studies. Bull Int Union Against Tuberc. 1970;43:322-31.

11. Mitchison DA. Chemotherapy of tuberculosis: a bacteriologist's viewpoint. BMJ. 1965;1:1331-8.

12. Espinal MA, Kim SJ, Suarez PG, et al. Standard short-course chemotherapy for drug-resistant tuberculosis: treatment outcomes in 6 countries. JAMA. 2000;283:2537-45.

13. World Health Organization. Toman's tuberculosis: case detection, treatment and monitoring, second edition. WHO, Geneva (2004). Available at: http: / / whqlibdoc. who.int/publications/2004/9241546034.pdf

14. World Health Organization. The treatment of tuberculosis: guidelines-4th ed. Document WHO/HTM/TB/2009.420. Geneva, WHO. 2010. Available at: http:// www.who.int/tb/publications/2010/en/

15. Albanna AS, Smith BM, Cowan D, Menzies D. Fixed-dose combination antituberculosis therapy: a systematic review and meta-analysis. Eur Respir J. 2013;42:721-32.

16. Sotgiu G, Mauch V, Migliori GB, Benedetti A. Evidence-based, agreed-upon health priorities to remedy the tuberculosis patient's economic disaster. Eur Respir J. 2014;43:1563-6. 
17. Weyer K, Mirzayev F, Migliori GB, et al. Rapid molecular TB diagnosis: evidence, policy making and global implementation of Xpert MTB/RIF. Eur Respir J. 2013;42:252-71

18. Sotgiu G, D'Ambrosio L, Centis R, et al. TB and M/XDR-TB infection control in European TB reference centres: the Achilles' heel? Eur Respir J. 2011;38:1221-3

19. Migliori GB, Sotgiu G, D'Ambrosio L, et al. TB and MDR/XDR-TB in European Union and European Economic Area countries: managed or mismanaged? Eur Respir J. 2012;39:619-25.

20. Raviglione M, Marais B, Floyd K, et al. Scaling up interventions to achieve global tuberculosis control: progress and new developments. Lancet. 2012;379:1902-13

21. Zignol M, van Gemert W, Falzon D, et al. Surveillance of anti-tuberculosis drug resistance in the world: an updated analysis, 2007-2010. Bull World Health Organ. 2012;90:111-9.

22. Matteelli A, Centis R, D'Ambrosio L, Migliori GB. Multidrug-resistant tuberculosis today. Bull World Health Organ. 2012;90:78.

23. Abubakar I, Dara M, Manissero D, Zumla A. Tackling the spread of drug-resistant tuberculosis in Europe. Lancet. 2012;379:e21-23.

24. Migliori GB, De Iaco G, Besozzi G, Centis R, Cirillo DM. First tuberculosis cases in Italy resistant to all tested drugs. Euro Surveill. 2007;12:E070517.1.

25. Udwadia ZF, Amale RA, Ajbani KK, Rodrigues C. Totally drug-resistant tuberculosis in India. Clin Infect Dis. 2012;54:579-81.

26. Velayati AA, Masjedi MR, Farnia P, et al. Emergence of new forms of totally drug-resistant tuberculosis bacilli: super extensively drug-resistant tuberculosis or totally drug-resistant strains in Iran. Chest. 2009;136:420-5.

27. Migliori GB, Centis R, D'Ambrosio L, et al. Totally drug-resistant and extremely drug-resistant tuberculosis: the same disease? Clin Infect Dis. 2012;54:1379-80.

28. Dara M, Kluge H. Roadmap to prevent and combat drug-resistant tuberculosis. Copenhagen, World Health Organization, Regional Office for Europe, 2011. Availableat:http:/ / www.euro.who.int/_data/assets/pdf_file/0014/152015/ e95786.pdf. [Accessed 28 October 2014].

29. Migliori GB, Dara M, de Colombani P, Kluge H, Raviglione MC. Multidrug-resistant tuberculosis in Eastern Europe: still on the increase? Eur Respir J. 2012;39:1290-1.

30. World Health Organization. Towards universal access to diagnosis and treatment of multidrug-resistant and extensively drug-resistant tuberculosis by 2015: WHO progress report 2011. Document WHO/HTM/TB/2011.3. Geneva, WHO 2011. Available at: http://www.who.int/tb/publications / 2011/mdr_report_2011/en/

31. Ahuja SD, Ashkin D, Avendano M, et al. Multidrug resistant pulmonary tuberculosis treatment regimens and patient outcomes: an individual patient data meta-analysis of 9,153 patients. PLoS Med. 2012;9:e1001300.

32. Falzon D, Jaramillo E, Schünemann HJ, et al. WHO guidelines for the programmatic management of drug-resistant tuberculosis: 2011 update. Eur Respir J. 2011;38:516-28.

33. WHO Companion handbook to the WHO guidelines for the programmatic management of drug-resistant tuberculosis. WHO/HTM/TB/2014.11. Geneva, WHO 2014. Available at: http:/ / www.who.int/tb/publications / pmdt_companionhandbook/en/

34. Gillespie SH, Crook AM, McHugh TD, et al. Four-month moxifloxacin-based regimens for drug-sensitive tuberculosis. N Engl J Med. 2014;371:1577-87.

35. Merle CS, Fielding K, Sow OB, et al. A four-month gatifloxacin-containing regimen for treating tuberculosis. N Engl J Med. 2014;371:1588-98.

36. Merle CS, Sismanidis C, Sow OB, et al. A pivotal registration phase III, multicenter, randomized tuberculosis controlled trial: design issues and lessons learnt from the Gatifloxacin for TB (OFLOTUB) project. Trials. 2012;13:61.

37. Jindani A, Harrison TS, Nunn AJ, et al. High-dose rifapentine with moxifloxacin for pulmonary tuberculosis. N Engl J Med. 2014;371:1599-608.

38. Andries K, Verhasselt P, Guillemont J, et al. A diarylquinoline drug active on the ATP synthase of Mycobacterium tuberculosis. Science. 2005;307:223-7.

39. Diacon AH, Pym A, Grobusch M, et al. The diarylquinoline TMC207 for multidrug-resistant tuberculosis. N Engl J Med. 2009;360:2397-405.
40. Diacon AH, Donald PR, Pym A, et al. Randomized pilot trial of eight weeks of bedaquiline (TMC207) treatment for multidrug-resistant tuberculosis: long-term outcome, tolerability, and effect on emergence of drug resistance. Antimicrob Agents Chemother. 2012;56:3271-6.

41. World Health Organization. The use of bedaquiline in the treatment of multidrug-resistant tuberculosis: interim policy guidance. Document: $\mathrm{WHO} /$ HTM/TB/2013.6. Geneva, Switzerland: WHO. 2013. Available at: http:/ / apps.who.int/iris/bitstream/10665/84879/1/9789241505482_eng.pdf

42. Mase S, Chorba T, Lobue P, Castro K. Provisional CDC guidelines for the use and safety monitoring of bedaquiline fumarate (Sirturo) for the treatment of multidrug-resistant tuberculosis. MMWR Recomm Rep. 2013;62:1-12.

43. Matsumoto M, Hashizume H, Tomishige T, et al. OPC-67683, a nitro-dihydroimidazooxazole derivative with promising action against tuberculosis in vitro and in mice. PLoS Med. 2006;3:e466.

44. Diacon AH, Dawson R, Hanekom M, et al. Early bactericidal activity of delamanid (OPC-67683) in smear-positive pulmonary tuberculosis patients Int J Tuberc Lung Dis. 2011;15:949-54.

45. Gler MT, Skripconoka V, Sanchez-Garavito E, et al. Delamanid for multidrug resistant pulmonary tuberculosis. N Engl J Med. 2012;366:2151-60.

46. Skripconoka V, Danilovits M, Pehme L, et al. Delamanid improves out comes and reduces mortality in multidrug-resistant tuberculosis. Eur Respir J. 2013;41:1393-400

47. World Health Organization. The use of delamanid in the treatment of multidrug-resistant tuberculosis. Interim policy guidance. Document $\mathrm{n}$. WHO/ HTM/TB2014.23. Geneva, WHO. 2014. Available at: http:/ / apps.who.int/iris / bitstream/10665/137334/1/WHO_HTM_TB_2014.23_eng.pdf?ua=1\&ua=1

48. Diacon AH, Dawson R, von Groote-Bidlingmaier F, et al. 14-day bactericidal activity of PA-824, bedaquiline, pyrazinamide, and moxifloxacin combinations: a randomised trial. Lancet. 2012;380:986-93.

49. Diacon AH, Pym A, Grobusch MP, et al.; The TMC207-C208 Study Group Multidrug-resistant tuberculosis and culture conversion with bedaquiline. N Engl J Med. 2014;371:723-32.

50. Diacon AH, Dawson R, von Groote-Bidlingmaier F, et al. Bactericidal activ ity of pyrazinamide and clofazimine alone and in combinations with pretomanid and bedaquiline. Am J Respir Crit Care Med. 2015;191:943-53.

51. Dawson R, Diacon AH, Everitt D, et al. The anti-tuberculosis activity of the combination of moxifloxacin, pretomanid (PA-824) and pyrazinamide during the first eight weeks of therapy: a Phase $2 \mathrm{~b}$ open label, partially randomized trial of efficacy, tolerability and safety in patients with drug-susceptible and drug-resistant pulmonary tuberculosis. Lancet. 2015. [Epub ahead of print]

52. Migliori GB, Eker B, Richardson MD, et al. A retrospective TBNET assessment of linezolid safety, tolerability and efficacy in multidrug-resistant tuberculosis. Eur Respir J. 2009;34:387-93.

53. Villar M, Sotgiu G, D'Ambrosio L, et al. Linezolid safety, tolerability and efficacy to treat multidrug-and extensively drug-resistant tuberculosis. Eur Respir J. 2011;38:730-3.

54. De Lorenzo S, Centis R, D'Ambrosio L, Sotgiu G, Migliori GB. On linezolid efficacy and tolerability. Eur Respir J. 2012;39:770-2.

55. Sotgiu G, Centis R, D'Ambrosio L, Spanevello A, Migliori GB; International Group for the study of Linezolid. Linezolid to treat extensively drug-resistant TB: retrospective data are confirmed by experimental evidence. Eur Respir J. 2013;42:288-90.

56. Sotgiu G, Centis R, D'Ambrosio L, et al. Efficacy, safety and tolerability of linezolid containing regimens in treating MDR-TB and XDR-TB: systematic review and meta-analysis. Eur Respir J. 2012;40:1430-42.

57. Srivastava S, Peloquin CA, Sotgiu G, Migliori GB. Therapeutic drug management: is it the future of multidrug-resistant tuberculosis treatment? Eur Respir J. 2013;42:1449-53.

58. Bolhuis MS, van Altena R, van Soolingen D, et al. Clarithromycin increases linezolid exposure in multidrug-resistant tuberculosis patients. Eur Respir J. 2013;42:1614-21.

59. Sotgiu G, Lange C, Richardson MD, et al. Comment on: Daily $300 \mathrm{mg}$ dose of linezolid for the treatment of intractable multidrug-resistant and extensively drug-resistant tuberculosis. J Antimicrob Chemother. 2009;64:879-83. 
60. Sotgiu G, Centis R, D'Ambrosio L, Castiglia P, Migliori GB. Low minimal inhibitory concentrations of linezolid against multidrug-resistant tuberculosis strains. Eur Respir J. 2015;45:287-9.

61. Sotgiu G, Pontali E, Migliori GB. Linezolid to treat MDR-/XDR-tuberculosis: available evidence and future scenarios. Eur Respir J. 2015;45:25-9.

62. De Lorenzo S, Alffenaar JW, Sotgiu G, et al. Efficacy and safety of meropenem-clavulanate added to linezolid-containing regimens in the treatment of MDR-/XDR-TB. Eur Respir J. 2013;41:1386-92.

63. Alsaad N, Wilffert B, van Altena R, et al. Potential antimicrobial agents for the treatment of multidrug-resistant tuberculosis. Eur Respir J. 2014;43:884-97.

64. Alsaad N, van Altena R, Pranger AD, et al. Evaluation of co-trimoxazole in the treatment of multidrug-resistant tuberculosis. Eur Respir J. 2013;42:504-12.

65. Krieger D, Vesenbeckh S, Schönfeld N, et al. Mefloquine as a potential drug against MDR-TB. Eur Respir J. 2015. [In press].

66. Sotgiu G, Migliori GB. Is tuberculosis elimination a reality? Lancet Infect Dis. $2014 ; 14: 364-5$.
67. Migliori GB, Sotgiu G. Measuring the effect of tuberculosis control: a step forward. Lancet. 2014;383:2026-8.

68. Tanimura T, Jaramillo E, Weil D, Raviglione M, Lönnroth K. Financial burden for tuberculosis patients in low-and middle-income countries: a systematic review. Eur Respir J. 2014;43:1763-75.

69. Diel R, Rutz S, Castell S, Schaberg T. Tuberculosis: cost of illness in Germany. Eur Respir J. 2012;40:143-51.

70. Diel R, Vandeputte J, de Vries G, Stillo J, Wanlin M, Nienhaus A. Costs of tuberculosis disease in the European Union: a systematic analysis and cost calculation. Eur Respir J. 2014;43:554-65.

71. Sotgiu G, Migliori GB. New effective antituberculosis regimens. Lancet. 2015. [Epub ahead of print].

72. Migliori GB, Lienhardt C, Weyer K, van der Werf MJ, Blasi F, Raviglione MC. Ensuring rational introduction and responsible use of new TB tools: outcome of an ERS multisector consultation. Eur Respir J. 2014;44:1412-7. 